\title{
ANÁLISE MORFOMÉTRICA E MORFOTECTÔNICA DO GRÁBEN DO RIO MAMANGUAPE E ADJACÊNCIAS, BORDA ORIENTAL DO ESTADO DA PARAÍBA, BRASIL
}

\author{
Max Furrier Furrier ${ }^{1}$ \\ Wesley Ramos Nóbrega ${ }^{2}$ \\ Alexandre dos Santos Souza ${ }^{3}$
}

Resumo: $O$ presente trabalho está fundamentado na utilização de três cartas topográficas na escala 1:25.000, que estão localizadas na borda oriental do estado da Paraíba, região Nordeste do Brasil. Com essa escala de detalhe, tornou-se possível um mapeamento inédito do gráben do rio Mamanguape, em seu médio e baixo curso. Inicialmente, a vetorização das cartas topográficas possibilitou a elaboração dos mapas temáticos e do Modelo Digital do Terreno (MDT), por meio dos quais obteve-se uma percepção particularizada de toda a configuração morfológica da área de estudo, que apresenta diferenças altimétricas discrepantes entre suas bordas norte e sul, percorrendo toda a adjacência do gráben. $O$ relevo da área apresenta vertentes em ombreiras ou shoulders, padrões assimétricos das redes de drenagem, orientações anômalas, inflexões bruscas de vários canais fluviais e recuos acelerados de cabeceiras de drenagem. Essas características atestam para um controle morfotectônico da área, haja vista que apenas o fator climático impossibilitaria o padrão morfológico encontrado.

Palavras-chave: Gráben do rio Mamanguape. Formação Barreiras. Tabuleiros Litorâneos.

\section{Morphometric and morphotectonic analysis of Mamanguape River gráben and adjacent areas, eastern border of the state of Paraiba, Brazil}

\begin{abstract}
This work is based on the use of three topographic maps in the scale 1:25.000, that are located on the eastern border of the State of Paraiba, northeastern Brazil. With the aid of such detail scale, it was possible to make an unprecedented mapping of the Mamanguape River gráben in its low and medium course. Initially, the topographic map vectoring made it possible the elaboration of thematic maps and the Digital Terrain Model (DTM), through which it was obtained a particularized perception of the whole morphological configuration of the area in question, which present altimetric discrepant differences from north to south along the adjacent areas of the gráben. The relief of the studied area shows hogbacks on shoulders, drainage network assimetric patterns, anomalous orientations, abrupt inflexions of various fluvial canals, and accelerated backings of drainage headwaters. These characteristics point to the existence of a morphotectonic control in the area, once only the climatic factor would make it impossible the formation of the morphological pattern found on it.
\end{abstract}

Keywords: Mamanguape river grabén. Barreiras Group. Coastal Tablelands.

\footnotetext{
${ }^{1}$ Professor Adjunto, Nível III - Departamento de Geociências/Centro de Ciências Exatas e da Natureza/Universidade Federal da Paraíba. E-mail: max.furrier@hotmail.com

${ }^{2}$ Geógrafo CREA-PB 1018140/14 - PostGraduate Program of Geographic Information Systems - Geospatial Management in Niagara College Canadá. E-mail: wesjppb@gmail.com

${ }^{3}$ Mestrando em Geografia/Centro de Ciências Exatas e da Natureza/Universidade Federal da Paraíba. E-mail: alesougeo@gmail.com
} 


\section{INTRODUÇÃO}

Este trabalho tem por objetivo apresentar as características morfotectônicas do gráben do rio Mamanguape e adjacências. A região corresponde às cartas topográficas de Itapororoca, Rio Tinto e Barra de Mamanguape, todas na escala 1.25.000, que seguem o sentido W-E em direção ao Oceano Atlântico, formando um complexo geomorfológico de estruturas distintas no relevo, na composição do terreno, na hidrografia e nos efeitos provocados pela ação da tectônica regional (FURRIER; ARAúJO; MENESES, 2006).

A caracterização morfotectônica está atrelada ao forte controle estrutural presente no Terreno Alto Pajeú (TAP) de idade Neoproterozóica, que forma o embasamento de toda a área de estudo, sendo desenvolvidos sobre ele, na porção leste, os Tabuleiros Litorâneos esculpidos, principalmente sobre a Formação Barreiras de idade Miocênica (BRITO NEVES et al., 2004; FURRIER; ARAUJO; MENESES, 2006).

Este terreno (TAP) foi afetado por movimentações no Cenozoico, que reativaram antigas linhas de falhas do Proterozoico, dando origem ao gráben do rio Mamanguape, que se apresenta perpendicular à linha de costa atual (BRITO NEVES et al., 2004). O TAP, bem como os terrenos limítrofes, são afetados por linhas de falhas reativadas do embasamento que foram preenchidas, em muitos casos, pelos cursos d'água regionais. Dentre esses rios, está o rio Mamanguape, que se apresenta alinhado a um sistema de falhas normais modernas de sentido WSW-ESE (BRITO NEVES et al., 2008).

\section{ÁREA DE ESTUDO}

A área de estudo compreende uma faixa emersa de aproximadamente $38 \mathrm{~km}$ de extensão por 14 $\mathrm{km}$ de largura, perfazendo uma área de $532 \mathrm{~km}^{2}$. Todo o compartimento está inserido na microrregião do Litoral Norte Paraibano, sendo o rio Mamanguape a drenagem de maior expressão, formando no seu baixo curso um extenso manguezal que se encontra com o Oceano Atlântico (Fig. 1). 


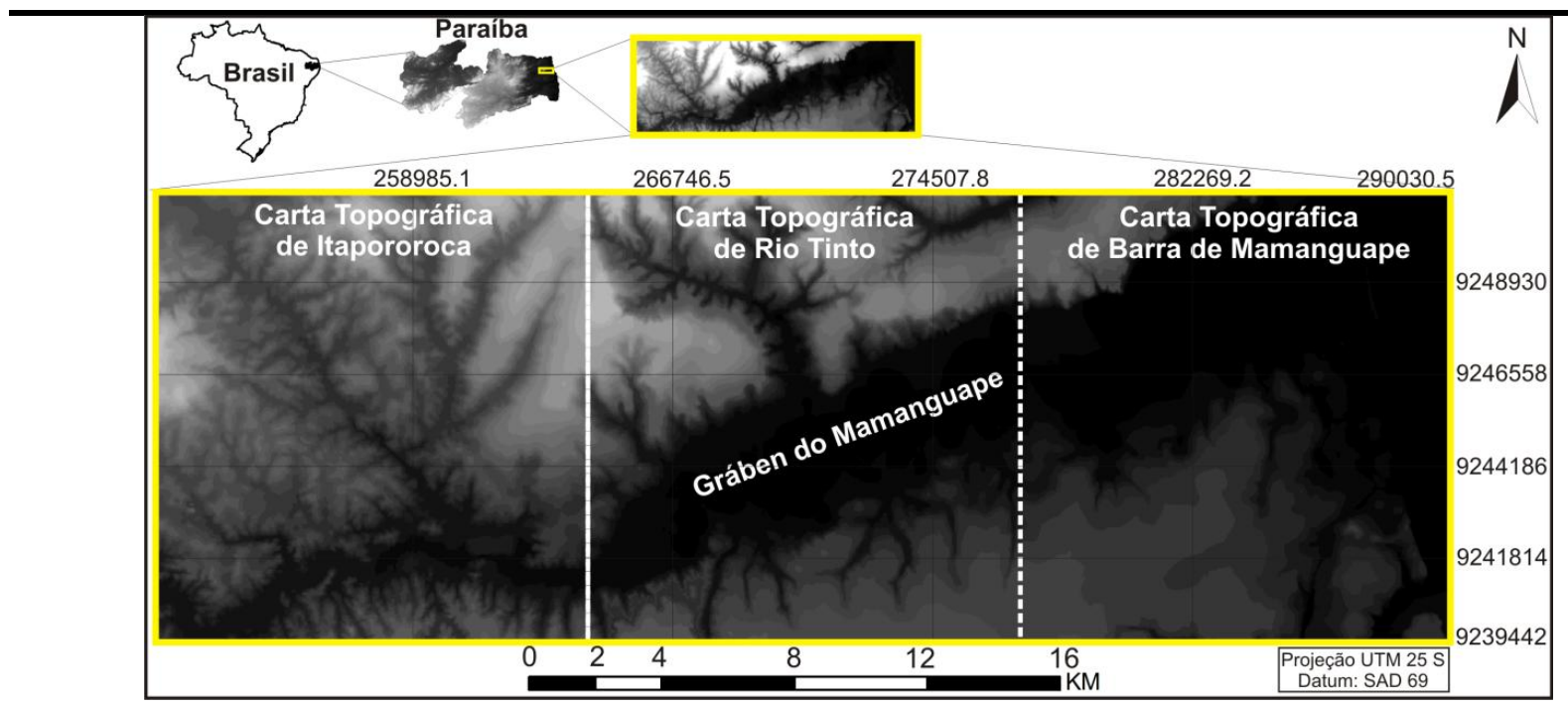

Fig. 1 - Localização da área de estudo elaborada a partir do Modelo Numérico do Terreno (MNT), produzido por meio da utilização das três cartas topográficas utilizadas neste trabalho.

\section{Contexto geológico e geomorfológico}

De acordo com o mapa geológico do estado da Paraíba, escala 1:500.000 (SANTOS; FERREIRA; SILVA JUNIOR, 2002), a região que compreende a área de estudo (Fig. 2) é constituída por um compartimento litótopo composto por feições distintas que estão presentes no embasamento neoproterozoico do Terreno Alto Pajeú (TAP), que engloba parte da província da Borborema e avança por debaixo da Formação Barreiras e da Bacia Sedimentar da Paraíba no setor centro-leste da área de estudo.

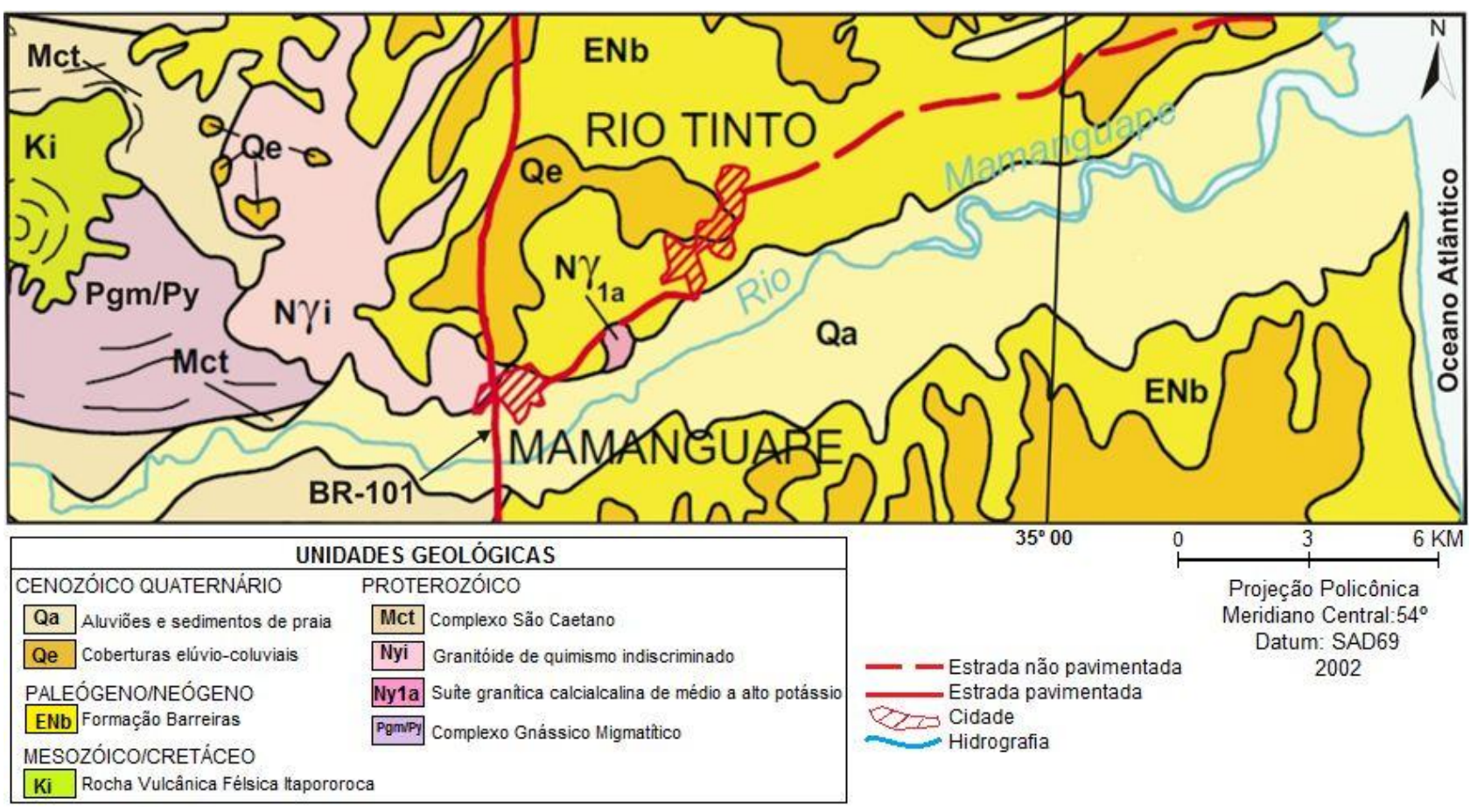

Fig. 2 - Carta geológica da área de estudo. Modificado de Santos, Ferreira e Silva Junior (2002). 
A área estudada é constituída por sedimentos areno-argilosos mal consolidados, depositados por sistemas fluviais entrelaçados dando origem à Formação Barreiras (ENb) e depósitos quaternários, principalmente os confinados pelo gráben. O embasamento proterozoico que forma o TAP abrange as duas cartas topográficas situadas no setor central e oeste, mas sua área de exposição é majoritária apenas na carta Itapororoca a oeste.

Na carta geológica da área de estudo (Fig. 2), apresenta-se com distinção a passagem do domínio da Formação Barreiras para o embasamento cristalino localizado a oeste no médio curso do rio Mamanguape, onde é cortado, perpendicularmente, pela BR-101, da qual se podem avistar exposições de rochas do embasamento cristalino face a face, em mesma cota, com os depósitos sedimentares da Formação Barreiras (BRITO NEVES et al., 2004).

Brito Neves et al. (2008) ainda afirma que no bloco alto da falha de Mamanguape apresentam-se as raras exposições do embasamento pré-cambriano, estando aflorando em suas vertentes rochas de natureza metagrauváquicas do TAP e um conjunto de rochas graníticas.

Toda a região está situada entre os lineamentos Patos e Pernambuco, na megaestrutura da Zona Transversal, onde se insere o TAP, cujo arcabouço é composto por unidades gnáissicas paleoproterozoicas, metaplutônicas, metavulcanossedimentares e granitoides, que estão arranjadas entre zonas de cisalhamento transcorrentes associadas ao evento Brasiliano (SANTOS; NUTMAN; BRITO NEVES, 2004).

De acordo com o mapa geológico do estado da Paraíba (SANTOS; FERREIRA; SILVA JUNIOR, 2002), são encontradas na região estudada rochas do complexo gnássico-migmatito (Pgm/py retrabalhados no Meso e Neoproterozoico); vulcânica félsica Itapororoca (Ki - sem dados geocronológicos, sendo atribuída uma idade Cretácea por correlação com o vulcanismo da Bacia do Cabo - PE); granitoide de quimismo indiscriminado ( $\mathrm{N}$ i); suíte granítica calcialcalina ( $\left.\mathrm{Ny}_{1 \mathrm{a}}\right)$; coberturas eluvio-coluviais; aluviões "(Qa - representados pelos aluviões do rio Mamanguape e rios adjacentes); e Formação Barreiras (ENb - apresentando estratificações tabulares/planares, muitas vezes falhadas).

O gráben do rio Mamanguape encontra-se condicionado às zonas de cisalhamentos detalhadas nos trabalhos de Brito Neves et al. $(2004,2008)$ supracitados. Dessas falhas, destaca-se a zona de caráter sinistral de Mulungu-Violeta (SW-NE), Mari Barro-Branco ou do rio Gurinhenzinho ao sul, e o trecho norte do lineamento Galante-Guarabira (BRITO NEVES et al., 2004).

Segundo Brito Neves et al. (2004), a "tectônica distencional", ocorrida na área após o arqueamento pós-Cretáceo Superior, surgiu em razão das antigas zonas de falhas pré-cambrianas (Fig. 3), 
apresentadas como sendo de cisalhamento simples e de transpressão, do final do Neoproterozoico ao início do Cambriano, que estiveram ativas durante a cratonização da Província Borborema.

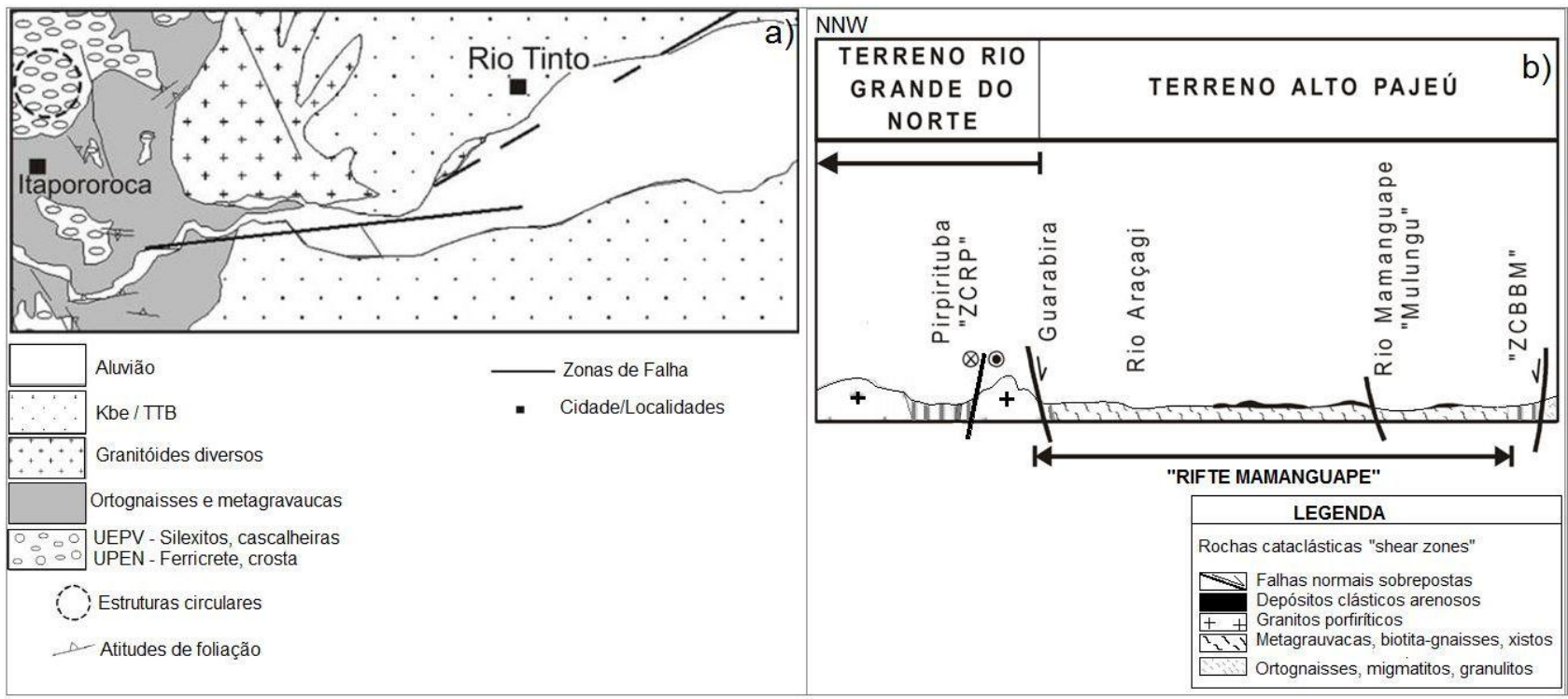

Fig. 3 - (a) Recorte extraído do esboço geológico apresentado por Brito Neves et al. (2008), apresentando as linhas de falhas que condicionam o gráben. (b) Recorte da seção geológica esquemática apresentada por Brito Neves et al. (2004) do Sistema Tafrogênico Terciário do Saliente Oriental Nordestino na Paraíba.

O gráben do rio Mamanguape, segundo Brito Neves et al. (2004), apresenta um preenchimento sedimentar descontínuo, em razão da ação do ciclo erosivo recente, sendo constituído principalmente por depósitos rudáceos, conglomerados, lamitos seixosos a arenosos e arenitos relacionados provavelmente a sistemas de leques aluviais e planícies de rios entrelaçados. Dessa forma, "as análises morfométricas permitem identificar anomalias no padrão destas feições, que evidenciam movimentações tectônicas recentes, e que nem sempre são visíveis na superfície" (HARTWIG; RICCOMINI, 2010).

Nesta perspectiva, a geomorfologia se diferencia radicalmente em razão do substrato presente em cada área, além dos rios estarem entalhando principalmente em áreas cujo compartimento é excepcionalmente sedimentar. Além disso, os tributários do rio Mamanguape, inseridos em zona de ambiente cristalino, apresentam-se tectonicamente encaixados, conforme Brito Neves et al. (2008) observa o encaixe de todos os tributários do Rio Seco.

No compartimento litótopo observa-se uma intensa modelagem do relevo, exercida pelos cursos de água atuais, que, sob a ação da gravidade, propiciam a esculturação morfológica presente. Ao longo de todas as cartas topográficas, desde a passagem dos substratos até o início e o fim do gráben do rio Mamanguape, constata-se um comportamento de um teclado de piano, com setores soerguidos e rebaixados alternadamente, separados pelo principal rio perpendicular à linha da costa (FURRIER; ARAUJO; MENESES, 2006). Esta morfologia aplica-se fielmente à porção estudada, 
por possuir áreas soerguidas e rebaixadas, no que compreende os compartimentos que estão separados pelo rio Mamanguape.

O domínio dos Tabuleiros Litorâneos ao norte e ao sul do gráben apresenta as características estruturais relacionadas às reativações tectônicas cenozoicas. Segundo Furrier, Araújo e Meneses, (2006), essas áreas são caracterizadas por soerguimentos distintos e basculamentos nos diferentes níveis dos entalhes fluviais e no padrão assimétrico de muitas redes de drenagem. $\mathrm{O}$ arcabouço estrutural também influenciou fortemente o padrão dessas redes de drenagem local e, consequentemente, a disposição dos tabuleiros.

A área mais elevada, localizada na porção norte do gráben, representa o alto estrutural de Mamanguape (FEITOSA; FEITOSA; LIRA, 2002), que teria servido de barreira ao avanço da sedimentação clástica continental precedente do sul, sendo considerado, portanto, como limite norte da Formação Beberibe e dos carbonatos da Formação Gramame pertencentes a Bacia Paraíba. Sobre esse alto existem apenas os arenitos calcíferos e manchas isoladas de calcarenitos resultantes do máximo transgressivo que cobriu essa área (BARBOSA, 2004).

\section{MÉTODOS E TÉCNICAS}

Este trabalho está fundamentado na elaboração de produtos cartográficos digitais, desenvolvidos a partir da vetorização de três cartas topográficas na escala de 1:25.000, com equidistância entre as curvas de nível de $10 \mathrm{~m}$.

As cartas utilizadas foram: Itapororoca (SB.25-Y-A-V-4-NO), Rio Tinto (SB.25-Y-C-III-3-NE) e Barra de Mamanguape (SB.25-Y-A-VI-3-NO). As cartas mencionadas foram também utilizadas na elaboração da carta hipsométrica e clinográfica (Fig. 5a e 5b) e do Modelo Digital do Terreno (MDT) (Fig. 6).

Para a elaboração da carta clinográfica foram adotadas as classes de declividade proposta por Herz e De Biase (1989). As definições das classes de declividades usadas neste trabalho estão amarradas às classes e limites usados internacionalmente (Quadro 1), bem como a trabalhos desenvolvidos por institutos de pesquisa nacionais e a leis vigentes no Brasil (Lei no.4.771/65 e Lei no. 6.766/79).

As cartas topográficas foram digitalizadas em formato JPEG, permitindo sua importação para o software livre DraftSight, com o intuito de realizar a vetorização dos elementos cartográficos necessários para serem exportados para o software livre Spring, versão 5.1.7, possibilitando a 
confecção das cartas temáticas (hipsométrica e clinográfica) e do MDT, que foi gerado a partir da imagem em nível cinza interpolada a partir das curvas de nível e pontos cotados vetorizados.

\begin{tabular}{cc}
\hline & CLASSES DE DECLIVIDADE \\
\hline EM PORCENTAGEM & EM GRAUS \\
\hline$<12 \%$ & $<7,250$ \\
$12 \%-30 \%$ & $7,25 \%-170$ \\
$30 \%-47 \%$ & $170-25 \circ$ \\
$47 \%-100 \%$ & $250-45 \circ$ \\
$>100 \%$ & $>450$ \\
\hline Quadro $1-$ Classes de declividade propostas por Herz e De Biasi (1989).
\end{tabular}

\section{RESULTADOS}

Na região correspondente à carta topográfica de Itapororoca (porção oeste da área de estudo), foi observada altimetrias superiores a $170 \mathrm{~m}$, tanto a NW do rio Seco quanto a NE do riacho Luís Dias, com presença de morros com superfícies levemente arredondadas, vales e desníveis característicos de uma zona afetada por esforços de compressão e tensão, criando uma modelagem típica de áreas onde o falhamento tectônico teve influência fundamental na configuração do relevo e na rede hidrográfica, conforme verificado no rifteamento que configura o vale do rio Mamanguape no seu médio curso (Fig. 4 e 5a).

Ao nordeste da carta de Itapororoca o rio Santa Cruz, bem como os riachos Luís Dias e Seco, são evidências de uma provável ação tectônica ocorrida no local, pois tanto o rio como os dois riachos citados apresentam sentidos discordantes do padrão de drenagem regional (Fig. 4, 5a e 6). Dentre essas peculiaridades, Brito Neves et al. (2008) observam a forma como os tributários do rio Seco estão bem encaixados em seus vales, no qual os riachos Luís Dias e Seco estão inseridos.

Ao noroeste a rede fluvial se projeta de maneira peculiar, com elevado gradiente hidráulico. A atuação desse gradiente nessa parte do terreno se estabeleceu principalmente no entorno do flanco erodido do episódio félsico Itapororoca. Essa estrutura é representada por um alto topográfico de bordas suaves e contorno ligeiramente alongado, com altimetria superior a $170 \mathrm{~m}$ em alguns pontos e com extensão longitudinal de aproximadamente 7 km (Fig. 4 e 5a). Essa morfologia é percebida no modo como afluem os riachos da área em direção ao rio Seco. 


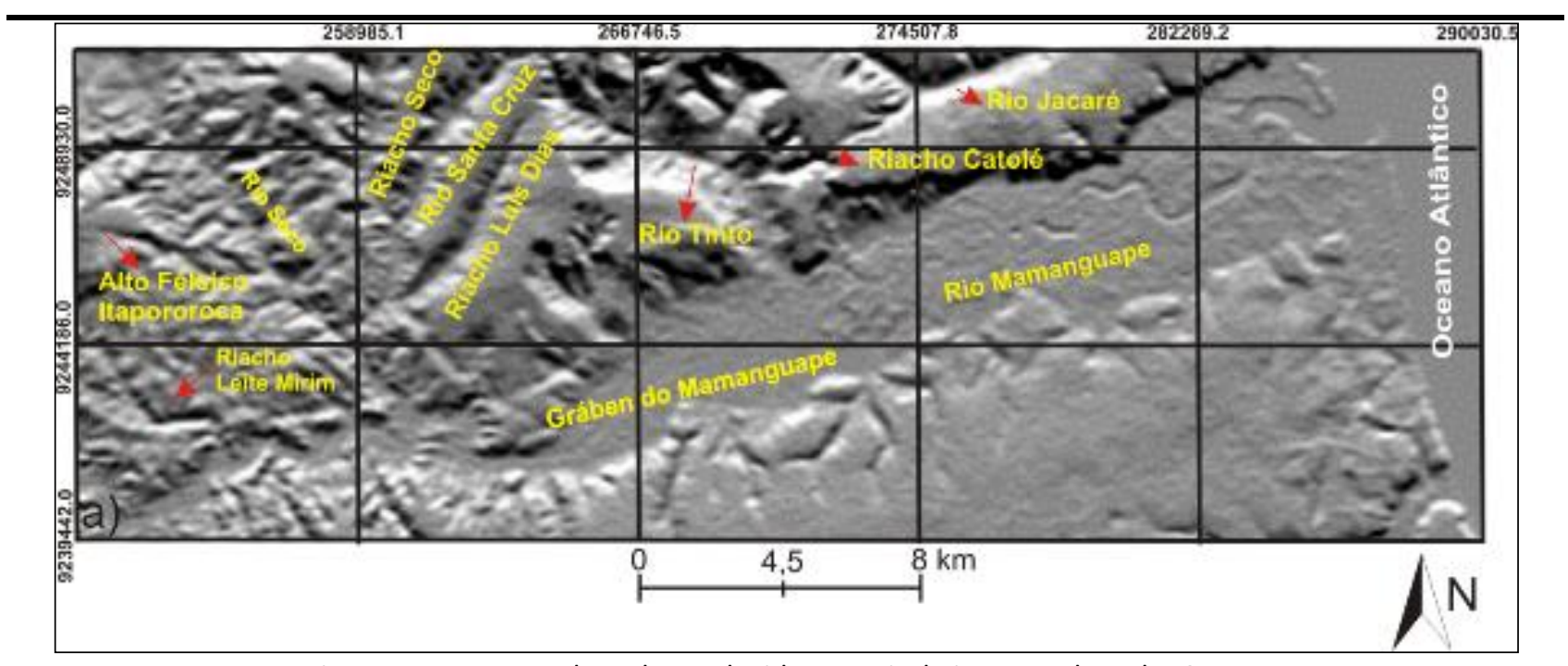

Fig. 4 - Imagem sombreada produzida a partir da imagem de radar SRTM.

Na parte central do gráben, onde está delineado o médio curso do rio Mamanguape, o fluxo segue para leste num padrão meandrante de padrão irregular. A drenagem fluvial é constituída por uma malha de afluentes pouco entalhados na porção sul do rio Mamanguape, onde a altimetria não excede $80 \mathrm{~m}$. Já na porção norte os rios são mais volumosos e acentuados, ajustados por linhas de falhas na estrutura da rocha ( $\mathrm{N}$ i), formando um padrão centrípeto que converge em direção ao rio Mamanguape.

Os resultados verificados contribuem significativamente no levantamento de evidências de um possível controle estrutural e tectônico sucedido no local, conforme observado no padrão da rede de drenagem. Sendo assim, essa possível morfotectônica, associada aos fatores exógenos, corroboram para a modelagem morfológica da área, constituindo compartimentos de formas distintas, não apenas na carta de Itapororoca, mas também nas cartas adjacentes utilizadas nesta pesquisa.

No setor compreendido pela carta topográfica de Rio Tinto (porção central da área de estudo), a imagem Shuttle Radar Topographic Mission (SRTM) e a carta hipsométrica (Fig. 4 e 5a), possibilitaram um entendimento bastante detalhado da área, mostrando duas características peculiares principais: o acentuado desnível altimétrico com os tabuleiros localizados na porção norte do gráben, possuindo altitudes de até $200 \mathrm{~m}$, e os localizados na porção sul, possuindo altitudes máximas de $80 \mathrm{~m}$, perfazendo, portanto, uma diferença altimétrica de $120 \mathrm{~m}$ entre os dois tabuleiros que confinam o gráben.

A carta clinográfica (Fig. 5b) mostra com grande nitidez os limites norte e sul do gráben, onde se observa declividades superiores na borda norte com frequências superiores a $47 \%$, além de exibir os elevados entalhamentos formados pelos rios Tinto e Jacaré (Fig. 5 b e 6), cujas vertentes 
alcançam até $100 \%$ de declividade, sendo esses dois rios fortemente encaixados em seus respectivos vales apontando intenso recuo de suas respectivas cabeceiras de drenagem.

Esses rios vêm exercendo seu papel de modelador do relevo com extrema eficácia, além de serem os grandes fornecedores de sedimentos para o interior do gráben do rio Mamanguape, onde ocorre o aluvionamento do canal.

O rio Jacaré, localizado na porção central da área de estudo, entalha fortemente o relevo, formando um vale encaixado com declividades superiores a $100 \%$ em alguns pontos de suas vertentes, principalmente nas proximidades de sua cabeceira, evidenciando um processo acelerado de recuo de cabeceira, que em um futuro próximo poderá acarretar em um processo de captura de drenagem junto à cabeceira do riacho Catolé, que atualmente dista a apenas $270 \mathrm{~m}$ da cabeceira de drenagem do rio Jacaré (Fig. 5a e 5b).

O rio Mamanguape, devido à diferença altimétrica entre os tabuleiros que o confinam, apresenta uma rede de drenagem extremamente assimétrica, com os rios oriundos dos tabuleiros localizados ao norte mais avantajados, entalhados e com recuos de cabeceiras bastante expressivos, formando vertentes com declividades muito mais superiores que os rios oriundos dos tabuleiros localizados ao sul do gráben.

Essa acentuada diferença entre os Tabuleiros Litorâneos que confinam o gráben do rio Mamanguape corrobora a ideia de reativações pós-cretácicas na área, visto que essa diferença altimétrica não pode ser explicada apenas pelo fator climático, pois toda a área se encontra sob o mesmo tipo de clima e pluviosidade similar, o que impossibilitaria a discrepância morfológica verificada.

Na carta topográfica Barra de Mamanguape (porção leste da área de estudo) é verificada a maior largura do gráben, com aproximadamente 5,12 km de extensão latitudinal. Também nessa porção são verificadas as discrepâncias altimétricas entres os tabuleiros localizados nas porções sul e norte, perfazendo uma diferença de $43 \mathrm{~m}$. Observa-se, também, um maior entalhamento dos vales fluviais com declividades muito mais superiores que os vales encontrados no setor sul (Fig. 5b). As declividades encontradas nas vertentes da porção norte do gráben apresentam declividades superiores às das vertentes da porção sul, com a presença bastante nítida de shoulders, facetas triangulares e escarpa de falha normal, características morfológicas relevantes de atividades neotectônicas. 

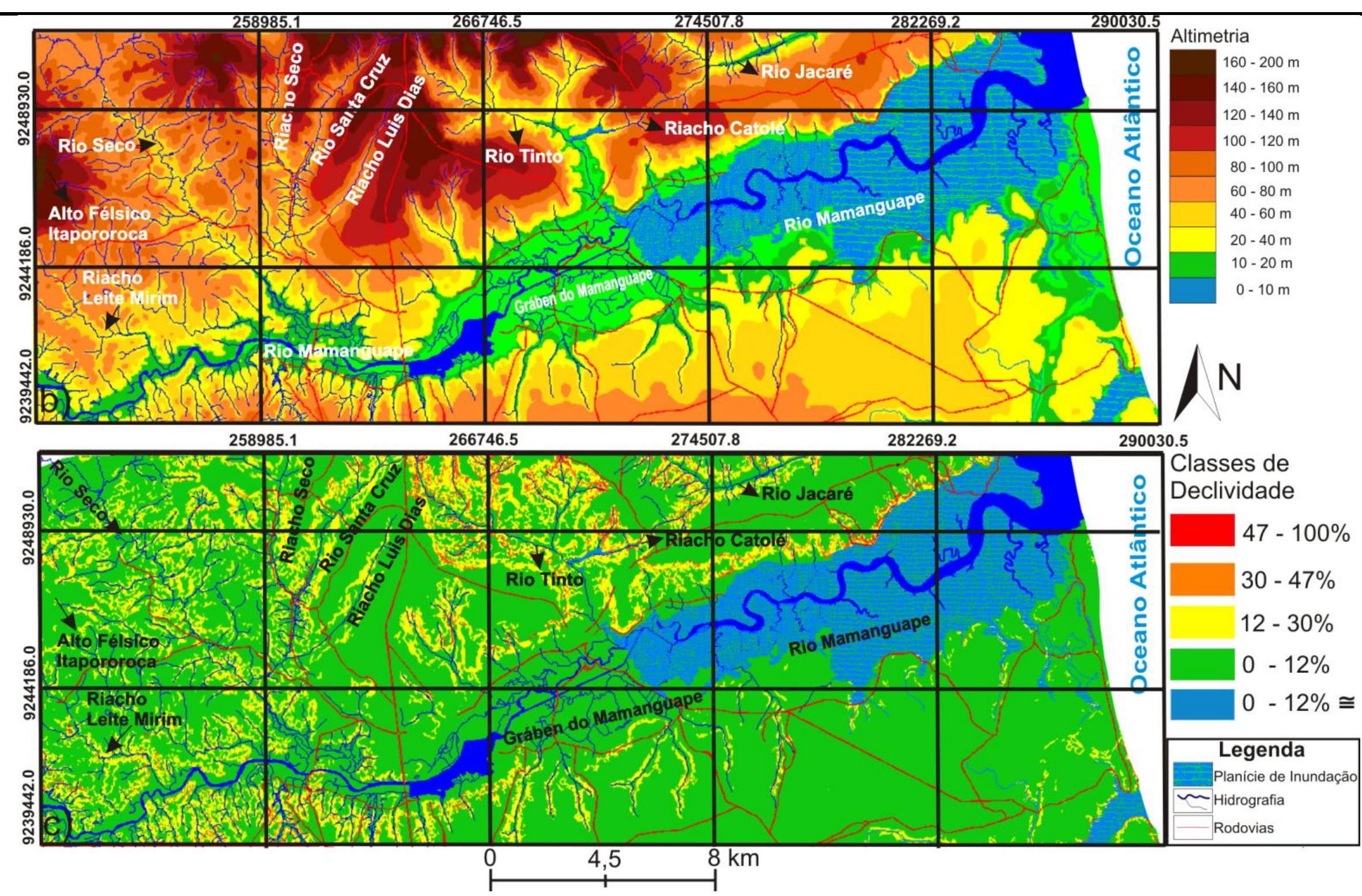

Fig. 5a - Carta hipsométrica. Fig. 5b - Carta clinográfica. Elaboradas a partir das cartas topográficas na escala de 1:25.000 no software Spring 5.1.7. 
A elaboração do Modelo Digital do Terreno (MDT) permitiu a visualização detalhada das várias nuances presentes no relevo da área sobre uma representação gráfica, na qual foi possível averiguar mais detalhadamente as discrepâncias altimétricas e peculiaridades morfológicas dos compartimentos (sedimentar e embasamento cristalino) onde se projetam sub-bacias hidrográficas distintas, a zona de rifteamento do rio Mamanguape (médio curso) e uma extensa área de mangue (no baixo curso), todos demonstrando estarem condicionados a uma linha de falha que controla o gráben do rio Mamanguape e suas imediações.

Outra situação morfológica que o MDT permitiu observar está no processo de dissecação ocorrido entre os principais afluentes do rio Mamanguape, sendo, portanto, as sub-bacias do rio Seco e do rio Tinto as mais expressivas. Essa dissecação característica de cada rio provém do substrato que compõe os seus cursos, uma vez que o primeiro rio está inserido num ambiente composto pelo embasamento cristalino, e o segundo em terreno sedimentar (Fig. 2).

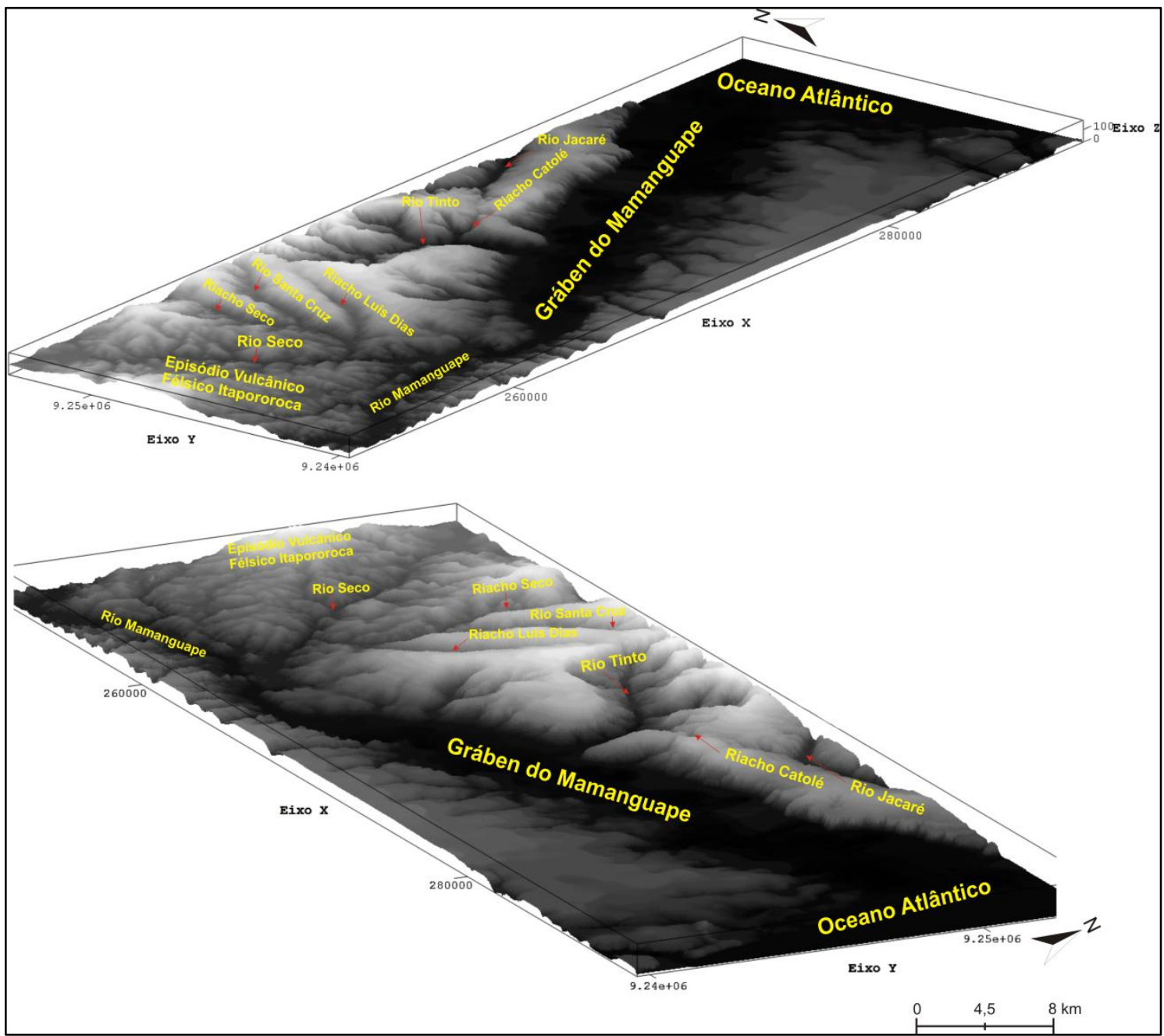

Fig. 6 - Modelo digital do Terreno (MDT) elaborado a partir da vetorização das cartas topográficas. 
Com esse mapeamento de detalhe, a presente pesquisa evidencia com forte embasamento, por meio dos resultados alcançados, que a área em questão apresenta sua morfologia estritamente atrelada ao fator neotectônico, pois as discrepâncias verificadas entre as porções norte e sul e o encaixe do rio Mamanguape não podem ser explicadas apenas pelos agentes exógenos. Portanto, estudos realizados no passado sem a óptica do controle tectônico sobre o relevo no Brasil devem ser revistos, principalmente os trabalhos geomorfológicos realizados na borda oriental do estado da Paraíba, cujo controle estrutural e morfotectônico é bastante conspícuo e relevante.

\section{CONSIDERAÇÕES FINAIS}

A interpretação das cartas temáticas possibilitou a constatação de inúmeras evidências de atividades neotectônicas na área de estudo, dentre elas, as principais são:

Carta Itapororoca (porção oeste):

$\checkmark$ O rio Santa Cruz e riachos Luís Dias e Seco apresentam sentidos discordantes do padrão de drenagem regional, ajustados por linhas de falhas na estrutura das rochas (Npi).

$\checkmark$ Presença de morros com superfícies levemente arredondadas a NW e vales encaixados a NE do rio Mamanguape com altitudes superiores a $170 \mathrm{~m}$.

$\checkmark$ Elevado gradiente hidráulico na porção NW da área, estabelecido principalmente no entorno do flanco erodido do episódio Itapororoca.

$\checkmark$ Presença de rios e riachos centrípetos mais volumosos e acentuados ao norte (encaixados nas falhas) e menos avantajados ao sul, convergindo em direção ao rio Mamanguape.

Carta Rio Tinto (porção central):

Acentuado desnível altimétrico com os tabuleiros localizados na porção norte do gráben, possuindo altitudes de até $200 \mathrm{~m}$.

$\checkmark$ Os rios Tinto e Jacaré apresentam vertentes com declividade superior a 100\%, sendo estes dois rios fortemente encaixados em seus respectivos vales.

$\checkmark$ Processo acelerado de recuo de cabeceira do rio Jacaré com a possibilidade de em um futuro próximo ocorrer uma captura de drenagem junto à cabeceira do riacho Catolé, que atualmente dista apenas $270 \mathrm{~m}$. 
Rede de drenagem extremamente assimétrica. Os rios oriundos dos tabuleiros localizados ao norte são mais avantajados, entalhados, e com recuos de cabeceiras bastante expressivos, formando vertentes com declividades muito mais superiores que os rios oriundos dos tabuleiros localizados ao sul do gráben.

Carta Barra de Mamanguape (porção leste):

Porção da área de estudo onde se projeta a maior largura do gráben com aproximadamente $5,12 \mathrm{~km}$ de extensão latitudinal.

$\checkmark$ Discrepância altimétrica entre os tabuleiros localizados nas porções sul e norte, perfazendo uma diferença de $43 \mathrm{~m}$.

$\checkmark$ Presença de shoulders, facetas triangulares e escarpa de falha normal, na porção norte do gráben, características conspícuas de atividades neotectônicas.

$\checkmark$ Afluentes da margem esquerda com vales mais entalhados e encaixados.

\section{REFERÊNCIAS}

BARBOSA, J. A. Evolução da Bacia Paraíba durante o Maastrichitiano-Paleoceno: Formações Gramame e Maria Farinha. Dissertação (Mestrado em Geociências) - Universidade Federal de Pernambuco, Centro de Tecnologia e Geociências, Recife: UFPE, 2004.

BRASIL. Lei no 4.771, de 15 de setembro de 1965. Institui o novo Código Florestal. Diário Oficial da República Federativa do Brasil, Brasília, DF, 16 set. 1965.

. Lei no 6.766, de 19 de dezembro de 1979. Dispõe sobre o Parcelamento do Solo Urbano e dá outras Providências. Diário Oficial da República Federativa do Brasil, Brasília, DF, 20 dez. 1979.

BRITO NEVES, B. B.; MANTOVANI, M. S. M.; MORAES, C. F.; SIGOLO, J. B. As anomalias geológicas e geofísicas localizadas ao norte de Itapororoca (PB), folha Guarabira. Revista Brasileira de Geociências, São Paulo, v. 38, p. 1-23, mar. 2008.

; RICCOMINI, C., FERNANDES, T. M. G; SANTANNA, L. G. O Sistema Tafrogênico terciário do Saliente Nordestino na Paraíba: um legado proterozóico. Revista Brasileira de Geociências, São Paulo, v. 34, n. 1, p. 127-134, mar. 2004. 
FEITOSA, E. C.; FEITOSA, F. A. C.; LIRA, H. M. P. Relações estratigráficas e estruturais entre a Bacia Potiguar e a Bacia Costeira PE/PB - uma hipótese de trabalho. CONGRESSO BRASILEIRO DE ÁGUAS SUBTERRÂNEAS, 12., Florianópolis. Anais... Florianópolis, 2002.

FURRIER, M.; ARAÚJO; M. E.; MENESES, L. F. Geomorfologia e tectônica da Formação Barreiras no estado da Paraíba, Geologia USP-Série Científica, São Paulo, v. 6, n. 2, p. 61-70, out. $2006 a$.

;__________ Geomorfologia e tectônica dos tabuleiros litorâneos no norte do estado da Paraíba. SIMPÓSIO NACIONAL DE GEOMORFOLOGIA, 6., Goiânia. Anais... Goiânia, 2006b.

HARTWIG, M. E.; RICCOMINI, C. Análise morfotectônica da região da Serra dos Órgãos, Sudeste do Brasil. Revista Brasileira de Geomorfologia, v. 11, n. 1, p.11-20, 2010.

HERZ, R.; DE BIASI, M. Critérios e legendas para macrozoneamento costeiro. Brasília: Ministério da Marinha/Comissão Interministerial para Recursos do Mar,1989.

SANTOS, E. J.; FERREIRA, C. A.; SILVA JUNIOR; J. M. F. Geologia e recursos minerais do estado da Paraíba: texto explicativo dos mapas geológico e de recursos minerais da Paraíba, 1/500 000. Recife, 2002.

; NUTMAN, A. P.; BRITO NEVES, B. B: Idades shrimp U-Pb do Complexo Sertânia: implicações sobre a evolução tectônica da Zona Transversal, Província Borborema. Revista do Instituto de Geociências-USP, São Paulo, v.4, p. 1-12, abr. 2004.

Artigo submetido em: 09/09/2013

Artigo aceito em: 08/06/2014 